Canadian Oncology

Nursing Journal

Revue canadienne

de soins infirmiers

en oncologie

Volume 29, Issue 1 - Winter 2019

elSSN: 2368-8076 


\section{Revision of an undergraduate nursing oncology course using the Taylor Curriculum Review Process}

\author{
by Catherine Mitchell and Catherine M. Laing
}

\begin{abstract}
Patients diagnosed with cancer require intensive nursing care and support across all healthcare settings (Canadian Association of Nurses in Oncology [CANO], 2015). Advances in this nursing specialty and the resulting changes to practice add to the complexity of the nursing role. Clinical improvements impact the preparation of nursing students transitioning into this area of practice. The inclusion of an oncology curriculum in undergraduate programs can help to develop fundamental competencies for undergraduates in this specialty (Lockhart et al., 2013). A fourth-year undergraduate nursing oncology course was recently evaluated at the University of Calgary to ensure content was congruent with current practice. Since the course was initially developed in 2011, there have only been minor updates, potentially resulting in out-of-date content. A curriculum review process outlined by the Taylor Institute of Teaching and Learning was used to complete this course revision (Dyjur a Kalu, 2016). The findings of this course revision indicate the need to provide more student-centred learning, to discuss the implementation of recent treatments, and to provide more clinically centered literature on recent developments in oncology.
\end{abstract}

\section{BACKGROUND}

W ith an estimated 206,200 newly diagnosed cases and 80,800 deaths from cancer in Canada in 2017 (Canadian Cancer Statistics Advisory Committee, 2017), it is evident that there is a demand to prepare our nursing workforce to meet the healthcare needs of cancer patients. Specialized oncology nursing education in Canada is typically offered through worksite orientation, apprenticeship, and continuing education programs following undergraduate education (CANO, 2015; Love, 2005). However, new nursing graduates and nurses without specialized oncology education will be required to provide care for cancer patients in various clinical settings (Lockhart et al., 2013). The Canadian Association of Schools of Nursing (CASN) National Nursing Education Framework (2015) outlines that the baccalaureate degree in nursing is designed to prepare a generalist nurse for entry to practise. CANO (2015) has defined the role of the generalist nurse as a nurse who is prepared at a basic educational level to care for cancer patients. In order to meet the guiding principles of the CASN National Nursing

\section{ABOUT THE AUTHORS}

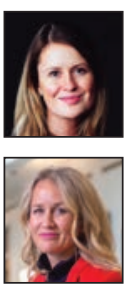

Catherine Mitchell, RN, MN, CON(C) (corresponding author),

Faculty of Nursing, University of Calgary

Email: catherine.mitchell@ucalgary.ca

Catherine M. Laing, RN, PhD, Assistant Professor, Faculty of

Nursing, University of Calgary
Education Framework within Canada, undergraduate programs need to incorporate oncology content to ensure patients across all healthcare settings are receiving adequate care.

Regrettably, many undergraduate nursing curricula lack an oncology course within Canada (CANO, 2015). This may put entry-level nurses at a disadvantage because there is a prevalence of cancer across all healthcare settings and not just in specialized areas. New graduates and nurses without oncology experience often practise in areas where they may be responsible for the care of an oncology patient (CANO, 2015). Therefore, entry-level competency to practise is critical to ensure patients with a diagnosis of cancer are receiving adequate care (CANO, 2015; Lockhart et al., 2013).

\section{COURSE REVISION PROCESS}

The revision of course content is critical to ensuring that content remains current and evidence-based (Dyjur \& Kenny, 2015). Course revisions are smaller in scope than a revision of an entire nursing curriculum, although they both require a similar process to be followed (Iwasiw \& Goldenberg, 2015). Course revisions should be conducted on an annual basis and involve an ongoing review of the course curriculum throughout each year (Iwasiw \& Goldenberg, 2015). Unfortunately, the literature on curriculum revisions does not provide a standardized approach to revising a single course, and each university may have a different approach to course revision. However, through the review of the literature, common themes can be identified in the curriculum revision process that can be applied to a course revision. These themes include the processes of curriculum mapping and collecting data from a variety of sources to support the potential changes. Curriculum mapping is an assessment tool used to determine how learning outcomes are taught and how they are aligned across a sequence of courses within an entire program (Dyjur \& Kenny, 2015). Collecting data from a variety of sources is necessary to provide evidence for the revisions (Iwasiw \& Goldenberg, 2015). Qualitative and/or quantitative methods can be employed to gather data, such as interviews, focus groups, and/or surveys (Iwasiw \& Goldenberg, 2015).

It should be stated that there is no literature on revising undergraduate nursing oncology courses. There were, however, several nursing articles discovered where the authors described the importance incorporating oncology content into undergraduate curriculum (Lockhart et al., 2013; Quinn-Casper \& Holmgren, 1987; Sarna \& McCorkle, 1995), but not the process of revising content. Despite the lack of literature, course revisions are a necessary process to ensure the content remains congruent with current research and practice (Iwasiw \& Goldenberg, 2015).

Teaching strategies. A major part of the course revision process is reviewing the effectiveness of the teaching strategies that are currently in place (Iwasiw \& Goldenberg, 2015). Ultimately, 
teaching strategies can be the difference between the students meeting the desired curriculum outcomes or not (Curran, 2014; Schaefer \& Zygmont, 2003). Teacher-centred and learner-centred approaches are used in nursing education to communicate the content of the curriculum to students. A teacher-centred approach promotes dependent learning where the student is a passive recipient of information through lectures and other didactic approaches to teaching (Schaefer \& Zygmont, 2003). Learnercentred teaching methods include methods such as case-based learning, group work, discussion, and debate (Curran, 2014; Kantar \& Massouh, 2015). Current research indicates there is a need to shift from teacher-centred approaches to learner-centred approaches (Curran, 2014; Condela, Dalley, \& Benzel-Lindley, 2006). This shift is based on evidence that a learner-centred approach improves the quality of learning because the focus is on the learning needs of the student (Curran, 2014; Condela et al., 2006). When students are in control of what they learn, they are actively engaged in the learning process, which has the potential to improve how they learn (Schaefer \& Zygmont, 2003).

\section{METHODS}

The fourth-year undergraduate oncology course offered at the University of Calgary is a three-hour class offered weekly over a 13-week semester. A curriculum review process outlined by the Taylor Institute for Teaching and Learning (Dyjur $\&$ Kalu, 2016) was used to revise this course. This curriculum review process was utilized to promote congruency among other programs within the University of Calgary. In addition, this process incorporated the steps of curriculum mapping and data collection, which were deemed as necessary components of revising a course in the literature (Dyjur \& Kenny, 2015; Iwasiw \& Goldenberg, 2015). The steps in this process are to be used for ongoing course appraisal and are utilized in the following order; guiding questions, curriculum mapping, data collection, data analysis, discussion, and action plan and implementation (Dyjur \& Kalu, 2016). It should be noted, however, that this process is intended for an entire curriculum, so it has been modified slightly to fit a single course review. In order to provide evidence to support potential changes to the course, a results section will be included after data analysis.

\section{Guiding Questions}

The first step in this process is asking guiding questions that define the investigation and identify what data may be useful in the course review (Dyjur \& Kalu, 2016). Some examples of guiding questions used to initiate this course review include, "What are the strengths of the current course?" and "What are the students expected to learn at the completion of this course?"

\section{Curriculum Mapping}

Curriculum mapping is an assessment tool used to align overall program outcomes with specific course outcomes within the program (Dyjur \& Kenny, 2015). Learning outcomes can be written at the program, course, or lesson level (Dyjur $\&$ Kenny, 2015). Course learning outcomes outline the content in a specific course, whereas program level learning outcomes are the overall objectives students are required to meet at the completion of their academic program (Dyjur \& Kenny, 2015).
In the oncology theory course, there are nine course learning outcomes and corresponding lesson objectives to be met in the course outline. Through the process of curriculum mapping, the course learning outcomes were aligned with the required program level learning outcomes to ensure congruency.

\section{Data Collection}

A variety of data was collected during this course revision using current literature, faculty feedback, and student focus groups. Current literature was accessed to provide evidence that the changes to the course are supported by evidence-based research. A review of the literature on curriculum evaluation, oncology nursing education, and teaching strategies was completed. Faculty feedback was gathered through one-on-one interviews. A purposeful sample $(n=7)$ was taken from faculty members involved with the oncology course, either from teaching (theory and clinical practice), development, or administrative perspectives. Faculty members were asked questions related to current strengths, challenges, and areas for potential change in the course. A convenience sample $(n=9)$ of students enrolled in the oncology course in the Spring/Summer and Fall 2016 semesters were used for the focus groups (Table 1).

\begin{tabular}{|c|c|}
\hline Table 1: Partici & \\
\hline Participant 1 & Student \\
\hline Participant 2 & Student \\
\hline Participant 3 & Student \\
\hline Participant 4 & Student \\
\hline Participant 5 & Student \\
\hline Participant 6 & Student \\
\hline Participant 7 & Student \\
\hline Participant 8 & Student \\
\hline Participant 9 & Student \\
\hline Participant 10 & Teaching \\
\hline Participant 11 & Developed course \\
\hline Participant 12 & Faculty Administrator \\
\hline Participant 13 & Teaching \\
\hline Participant 14 & Taught previously \\
\hline Participant 15 & Clinical Instructor \\
\hline Participant 16 & Clinical Instructor \\
\hline
\end{tabular}

The focus groups were both 40 to 60 minutes in length. Once students consented, the focus group conversations were audio recorded and transcribed verbatim for the data analysis. During each focus group the students were asked a set of 15 open-ended questions related to aspects of the course that they found most helpful and modifications to this course they felt could be beneficial (Table 2). 


\section{Table 2: Student Focus Group Questions}

1. What were your expectations of this course?

2. Of the content you learned, what have you found most useful in the clinical setting?

3. What content has been the least useful in the clinical setting?

4. How do you feel about the course structure/workload? Did you have enough time to complete assignments?

5. What do you like best about the course?

6. What is a key strength of the course?

7. What current strengths should the course build upon?

8. What key improvement could be made to the course? Why do you feel this area requires improvement?

9. What two key changes would you suggest if you were to revise the course?

10. What would you like to change about the course?

11. Did you notice any content in your clinical settings that wasn't covered in the theory class?

12. Do you have any suggestions to improve the strategies that were used for teaching in the course?

13. In what ways did this course prepare you for your future career in nursing?

14. How does the content in this course fit with other content in your nursing studies?

15. What is the most important thing you would tell a curriculum committee to enhance/change/address in this course?

\section{Data Analysis}

Part of a course review is identifying patterns and trends in the data that will assist in the revisions. This curriculum review process (Dyjur \& Kalu, 2016) does not offer a standardized way to analyze interview and focus group data. Therefore, the decision was made to utilize a thematic analysis approach to assist with data analysis. The interview and focus group data were reviewed using a thematic analysis approach outlined by Braun and Clark (2006). The approach described by Braun and Clarke (2006) outlines six steps to follow when conducting a thematic analysis. These steps include: 1) familiarizing yourself with the data; 2) generating initial codes; 3) searching for themes; 4) reviewing themes; 5) defining and naming themes; and 6) producing the report. Thematic analysis was utilized because it is a method used to describe, analyze, and identify themes and patterns within data (Braun \& Clarke, 2006), which is necessary to implement changes to course content (Dyjur \& Kalu, 2016).

\section{RESULTS}

The results from the student focus groups and faculty interviews revealed three main themes and several subthemes related to this course review. The main themes included teaching strategies, assignments, and content.

Teaching strategies. Students emphasized in both focus groups that they wanted to have more interactive methods of teaching, such as case study activities and class discussions. One student stated, "That would have been nice if the class had case studies that said this is your patient, and like what treatment modality would you expect?" (Participant 1). Another student added that having case studies would be helpful in applying the theoretical knowledge gained in class because "it's not obvious in practice, you know like it's not always going to be straight forward" (Participant 3). The students also frequently expressed the value in having more class discussions to stimulate critical thinking. Specifically, they felt that a more interactive teaching strategy would yield a higher retention of learned material, "I learned more in terms of critical thinking when we would have the opportunity to ask questions" (Participant 4). Faculty members also felt that more time for class discussions and questions would help to stimulate student learning and knowledge application.

Assignments. With respect to this oncology course, both students and faculty articulated the need for an updated and refocused presentation assignment. Students felt the presentation assignment, where they were asked to explore common themes experienced by patients and their families and apply the CANO standards to those themes, could be made more valuable to their learning. One student was perplexed on the point of the assignment, "What point are we trying to get to with this presentation assignment? Like what is, is this a specific thing that we should be trying to demonstrate?" (Participant 4). This was further confirmed by a student stating, "the presentation, I still am kind of confused as to what we're supposed to get out of it" (Participant 2). Other students felt that this assignment could build on their knowledge of different types of cancers, "I just don't understand, why wouldn't they just give us a cancer and we present on a specific type of cancer" (Participant 1). Faculty members felt that the assignments could be modified to incorporate more patient teaching examples or even adding in a case study assignment where the students present the information to the rest of the class.

Content. Faculty members and students expressed the need to update required readings and incorporate newer treatment options that are currently being used in practice settings. The students agreed that treatments, such as biotherapy, needed to be incorporated into the class content. One student stated, "Biotherapy in general would be good to include and like, understanding the side effects behind it, because I have seen patients with like the different facial rash and you're like 'oh what causes that?"” (Participant 2).

\section{Discussion}

Findings of this course revision align with current best practice of shifting away from a didactic teaching approach toward a more learner-centred approach to improve the quality of learning (Condela et al., 2006; Curran, 2014; Schaefer \& Zygmont, 2003). Implementing student-centred learning approaches, such as class discussion and case studies, allows for students to apply the theoretical knowledge gained in the classroom to a specific case study (Kantar \& Massouh, 2015). This application of knowledge can assist students in transferring this insight into their own clinical practice (Kantar \& Massouh, 2015; Knowles, Holton, \& Swanson, 2011).

Both students and faculty articulated the need for an updated and refocused final presentation. Having an activity that addresses the learning needs of the students is important 
to their knowledge transfer and development (Knowles et al., 2011). As a result, it is important that the course assignments are relevant to the student learning needs.

Faculty members and students expressed the need to update required readings and incorporate newer treatment options that are currently being used in practice settings. Specifically, biotherapy is a promising treatment used in combination with many chemotherapy regimens (National Cancer Institute, 2013). Although some biotherapy agents have been around for decades, there are multiple new biotherapy treatments being introduced regularly in the oncology setting (National Cancer Institute, 2013). This is reflected in the results of the data, as many of the students and faculty members mentioned the importance of including this particular therapy in class content. Implementing a class on this treatment is an important step in ensuring the students are receiving current knowledge in the field of oncology and will therefore be more prepared for the practice setting.

\section{Action Plan and Implementation}

An action plan was created to outline the suggested changes to be implemented in future course offerings. This is a necessary component of the curriculum review process that provides a concise summary of the recommended changes based on the data analysis and collection (Dyjur \& Kalu, 2017). These changes included: introducing content on newer treatments; modifying the presentation assignment to reflect student and faculty feedback; and updating the required readings to demonstrate current practice.

Biotherapy content. In order to reflect the feedback received from students and faculty, and provide insight into current practice in the field of oncology, a class on biotherapy agents was created. The content of this biotherapy class has been designed to provide the students with an overview of biotherapy agents and a review of the functions of the immune system. The class is structured to incorporate learner-centred approaches, addressing the need for more interactive teaching strategies (Iwasiw \& Goldenberg, 2015). The content includes discussion questions, multiple choice questions, and case studies on each biotherapy agent. This has the potential to expose the students to a variety of perspectives, encourage teamwork, and enhance critical thinking skills.

Presentation assignment. Based on this course review, the group presentation assignment was modified to fit the learning needs of the students as outlined in the focus group data. This assignment has been modified to ask the students to pick a common cancer diagnosis from their clinical setting. Students will split up into small groups and present the cancer diagnosis, potential treatment plan (including a treatment protocol example), supportive medications, and a patient teaching example. Changing the goal of the presentation assignment emphasizes a student-centred approach to learning, as the students will be presenting and teaching to their classmates about a specific cancer diagnosis and treatment plan.
Required readings. The required readings for each class have been updated to reflect current best practice and knowledge. Each reading has been updated to ensure that the content of the readings is reflected in the class.

\section{Updated Course Content}

Based on the course revision, the class content was modified to incorporate the recommended changes. See Table 3 for a week by week schedule of the current course including teaching strategies used. The first three classes are meant to build on foundational knowledge and explore the role of the oncology nurse, the disease and illness of cancer, and introduce the framework of patient centred care. The remaining weeks explore both the trajectory of the illness and the different treatment modalities that a cancer patient may encounter.

\begin{tabular}{|c|c|c|}
\hline \multicolumn{3}{|c|}{ Table 3: Course Content and Teaching Strategies } \\
\hline Week & Subject & Teaching Strategy \\
\hline Week 1 & $\begin{array}{l}\text { Oncology nursing: What is it } \\
\text { and who does it? Review of } \\
\text { cancer: The disease and illness }\end{array}$ & Lecture \\
\hline Week 2 & $\begin{array}{l}\text { Diagnosis and staging with a } \\
\text { focus on surgery }\end{array}$ & Lecture \\
\hline Week 3 & Supportive care framework & $\begin{array}{l}\text { Lecture content, } \\
\text { videos, class discussion }\end{array}$ \\
\hline Week 4 & $\begin{array}{l}\text { Radiation and the role of the } \\
\text { nurse }\end{array}$ & $\begin{array}{l}\text { Lecture content, case } \\
\text { studies }\end{array}$ \\
\hline Week 5 & $\begin{array}{l}\text { Chemotherapy and the role } \\
\text { of the nurse }\end{array}$ & $\begin{array}{l}\text { Lecture content, case } \\
\text { studies, class discussion }\end{array}$ \\
\hline Week 6 & $\begin{array}{l}\text { Biotherapy and the immune } \\
\text { system }\end{array}$ & $\begin{array}{l}\text { Lecture content, case } \\
\text { studies, group work, } \\
\text { videos and diagrams, } \\
\text { multiple choice and } \\
\text { open-ended questions, } \\
\text { class discussion } \\
\end{array}$ \\
\hline Week 7 & Pediatric oncology & $\begin{array}{l}\text { Lecture content, } \\
\text { videos, class discussion }\end{array}$ \\
\hline Week 8 & Oncologic emergencies & $\begin{array}{l}\text { Lecture content, } \\
\text { case studies, class } \\
\text { discussion, multiple } \\
\text { choice questions }\end{array}$ \\
\hline Week 9 & Blood and marrow transplant & Lecture \\
\hline Week 10 & Midterm exam & Multiple choice exam \\
\hline Week 11 & $\begin{array}{l}\text { Complementary and } \\
\text { alternative therapies in } \\
\text { oncology }\end{array}$ & Lecture \\
\hline Week 12 & $\begin{array}{l}\text { Survivorship and long-term } \\
\text { effects }\end{array}$ & Lecture \\
\hline Week 13 & $\begin{array}{l}\text { Student presentation } \\
\text { assignment }\end{array}$ & $\begin{array}{l}\text { Student led-learning } \\
\text { activity, group work, } \\
\text { case studies }\end{array}$ \\
\hline
\end{tabular}




\section{LIMITATIONS}

There were several limitations of this research project. One limitation is that the data collected from each focus group cannot be generalized to all nursing students. If the focus groups were with a different group of students, the outcome and answers to many of the questions could have resulted in different themes.

The method used to evaluate the course content can also be viewed as a limitation. The curriculum review process is designed to evaluate an entire program's curriculum and therefore, the overall method is designed to view curriculum from a much higher level. As a result, this process may fail to address the specificity and complexity of a single course.

Another limitation in this course revision was that recent graduates of the nursing program, who had attended in the oncology course prior to graduation, did not participate in a focus group. It may have been beneficial to see what areas of the course these individuals found most valuable to their practice, as new nurses.

\section{REFERENCES}

Braun, V., \& Clarke, V. (2006) Using thematic analysis in psychology. Qualitative Research in Psychology, 3, 77-101. doi:http://dx.doi. org/10.1191/1478088706qp063oa

Canadian Association of Nurses in Oncology. (2015). Professional development of Canadian nurses involved in cancer care. Retrieved from http://www.cano-acio.ca/ ASSETS/DOCUMENT/ professional\%20development\%20position\%20statement.pdf

Canadian Association of Schools of Nursing. (2015). National nursing education framework: Final report. Retrieved from http://www. casn.ca/wp-content/uploads/2014/12/Framwork-FINAL-SBNov-30-20151.pdf

Canadian Cancer Statistics Advisory Committee. (2017). Canadian cancer statistics 2017. Retrieved from http://www.cancer.ca/ / media/cancer.ca/CW/cancer\%20information/cancer\%20101/ Canadian\%20cancer\%20statistics/Canadian-Cancer-Statistics2017-EN.pdf?la=en

Condela, L., Dalley, K., \& Benzel-Lindley, J. (2006). A case for learningcentered curricula. Journal of Nursing Education, 45(2), 59-66. Retrieved from http://www.ncbi.nlm.nih.gov/pubmed/16496859

Curran, M.K. (2014). Examination of the teaching styles of nursing professional development specialists, part 1: Best practices in adult learning theory, curriculum development, and knowledge transfer. The Journal of Continuing Education in Nursing, 45(5), 233-240. doi:10.3928/00220124-20140417-04

Dyjur, P., \& Kenny, N. (2015). Analyzing curriculum mapping data: Enhancing student learning through curriculum redesign. Proceedings of the 2015 University of Calgary Conference on Postsecondary Learning and Teaching. Retrieved from http:// dspace.ucalgary.ca/bitstream/1880/50575/1/Proceedings_ Analyzing_Curriculum_Mapping_Data_UofC_conference_2015. pdf

Dyjur, P., \& Kalu, F. (2016). Introduction to curriculum review. Retrieved from http://curriculummapping.weebly.com/ uploads/1/4/9/0/14908434/introduction_to_curriculum_review.pdf

Dyjur, P., \& Kalu, F. (2017). Curriculum review: Action plan and final report. Calgary: University of Calgary

\section{CONCLUSION}

Ultimately, the goal of baccalaureate nursing education is to produce nursing graduates who can care for patients in diverse settings, including oncology (CANO, 2015). New research and technology advances so quickly that it poses difficulties in ensuring that the curriculum stays current. Performing continuous evaluation of course content after each course offering is an important step in confirming that the content and teaching strategies continue to be based on current research. The instructor(s) who teach the future course offerings can evaluate the course changes to determine if the changes have a positive impact on student learning. Future course revisions could also implement more interactive teaching strategies into each class. A course revision is one method of ensuring that content is current, based on provincial and national guidelines for oncology care, and provides the most effective strategies to enable students to practically apply the knowledge obtained.

Iwasiw, C.L., \& Goldenberg, D. (2015). Curriculum development in nursing education (3rd ed.). Burlington, MA: Jones \& Bartlett Learning.

Kantar, L.D., \& Massouh, A.R. (2015). Case-based learning: What traditional curricula fail to teach. Nurse Education Today, 35(8), e8e14. doi:10.1016/j.nedt.2015.03.010

Knowles, M.S., Holton, E.F., \& Swanson, R.A. (2011). The adult learner: The definitive classic in adult education and human resource development (7th ed.). Amsterdam, Boston: Elsevier, Butterworth-Heinemann.

Lockhart, J.S., Galioto, M., Oberleitner, M.G., Fulton, J.S., McMahon, D., George, K., ... Mayer, D.K. (2013). A national survey of oncology content in prelicensure registered nurse programs. Journal of Nursing Education, 52(7), 383-390. doi:10.3928/01484834-20130529-01

Love, B. (2005). Baccalaureate-linked oncology nursing education: McMaster University's Paediatric and Adult Oncology Nursing Program. Canadian Oncology Nursing Journal, 15(2), 80-93. doi:10.5737/1181912x1528086

National Cancer Institute. (2013). Biological therapies for cancer. About Cancer. Retrieved from https://www.cancer.gov/about-cancer/ treatment/types/immunotherapy/bio-therapies-fact-sheet

Quinn-Casper, P., \& Holmgren, C. (1987). Enhancing cancer nursing concepts in undergraduate curricula. Cancer Nursing, 10(5), 274-278. Retrieved from http://journals. lww.com/cancernursingonline/Abstract/1987/10000/ Enhancing_cancer_nursing_concepts_in_undergraduate.6.aspx

Sarna, L., \& McCorkle, R. (1995). A cancer nursing curriculum guide for baccalaureate nursing education. Cancer Nursing, 18(6), 445451. Retrieved from http://journals.lww.com/cancernursingonline/ Abstract/1995/12000/A_cancer_nursing_curriculum_guide_ for.4.aspx

Schaefer, K.M., \& Zygmont, D. (2003). Analyzing the teaching style of nursing faculty: Does it promote a student-centered or teachercentered learning environment? Nursing Education Perspective, 24(5), 238-245. Retrieved from http://www.ncbi.nlm.nih.gov/ pubmed/14535144 